especially if he had previously predicted the great tide of March I of the same year, which rose to 3 feet $\eta$ inches above the mark.

With respect to the actions of the planets, I did not refer to the ordinary tide-producing power, for on working that out some years ago for one of the planets I was somewhat surprised to find that the height was, I believe, a fraction of an inch. I referred rather to the action of that storm-producing power which apparently gives rise to the great atmospheric disturbances at certain times (and, indeed, more or less at all times) in the sun, and by sympathy, or even directly, in our a'mosphere.

B. G. JenKins

\section{Diffusion Figures in Liquids}

Pror. MARTINI"describes his diffusion figures as being "both new and singular." In the Phil. Mag. for June and November, r 864 , I have described and figured various examples of what call "the submersion figures of liquids" in continuation of a series of papers commenced in $186 \mathrm{r}$ on "The Cohesion Figures of Liquids," or those assumed by liquid drops when delivered to various surfaces. Some of these figures are identical with those given by Mr. Worthington in the Proceedings of the Royal Society for 1876 , and recently in your pages.

Highgate, N., December 3

\section{Bees and Flowers}

IN last Thursday's impression (p. 62) is a letter from Mr. H. O. Forbes, referring to bees confining their visits to plants of one kind during each excursion, and thus in a measure preventing hybridisation of plants, \&c.

This may be the general habit of bees, but it is not invariable; some bees, more especially their females, are to be found at certain plants only, as Andrena hattorfiana, at the scabious Colletes succincta, at the heath, and many others in like manner.

I have collected bees for several years, and have ofren taken them with the pollen-grains varying from orange-red to almost white, and this mixture on the same leg. I have inclosed a slide of pollen-prains which I washed from the leg of an Andrena ni, ro-checa, and mounted in balsam; this shows several very distinct kinds of pollen; this was mounted in 1875 , and at the time I gathered such of the wild flowers as were then in bloom, and compared the pollen. I was able to identify several of them, but as I made no notes I cannot say which. I would advise such observers as intend investigating this very interesting subject, to capture the insects and examine the pollen which may be found on them; this will be difficult in the case of the Bombi and Apis, as they knead it into pellets, but with those which collect on the belly or whole les it will be easy enough.

Norwich

JOHN B. BRIDGMAN

\section{Hearing in Insects}

My daughter bred this summer a number of the larva of Sphrinx ligustri and Metopsilus elepenor, and I was much struck with the extreme sensitiveness to the sound of the voiceespecially of the former. The child's treble I observed did not affect them so sharply; but at the first word. I uttered they invariably started, and remained some time motionless, with head drawn back, after their manner. I was disposed to attribute it to the vibration set up in objects around by sounds toward the deeper end of the scale, as I have felt a form tremble under me at the deep bass notes of a strong singer; but it had all the appearance and effects of hearing.

Bregner, Bournemouth, December I

\section{A ZOOLOGICALSTATION FOR THE CHANNEL ISLANDS}

SOME* definite prospect at length presents itself of the establishment within British waters of an institution long recognised as a leading desideratum among our Biologists, Museum-Conservators, and Natural History Students, namely, a building with the necessary appurtenances suitably situated, and founded on a somewhat similar basis to that of Dr. Anton Dohrn's noted Zoological Station at Naples, or the Anderson School of Natural History at Penikese Island, Buzzard's Bay, U.S. This long-felt need will be met by the proposed "Channel Islands' Zoological Station and Museum, and Institute of Pisciculture "described at some length in the advertising columns of this journal, and the establishment of which, or a similar institution, has been the guiding star and main object of the writer's ambition during the several years' "apprenticeship" spent by him as Naturalist and Curator to the various leading public aquaria of England.

Successfully carried out, the more prominent features of this undertaking will comprise, as at Naples, in addition to an attractive public exhibition of the living inhabitants of the surrounding waters, laboratories fitted with tanks, tables, and all the necessary instruments and apparatus requisite for the satisfactory prosecution of marine biological research, supplemented by a library replete with the standard scientific works and serials mostly in demand by those occupied in such investigation. Under the same roof it is likewise intended to establish a natural history museum accessible to the public, and more essentially illustrative of the notably rich marine fauna and flora of the Channel Islands. In connection with the library and museum departments popular lectures upon natural his!ory subjects will from time to time be given. Following the system productive of such gratifying results at the Penikese Island Station, it is further proposed for the full development of the scientific advantages of this institution to institute summer classes for the attendance of students, and to hold out sufficient inducements for the most eminent authorities on various biological subjects to deliver lectures and a course of instruction to these classes upon that branch of natural history with which their reputation is more especially associated.

An entirely novel feature to be incorporated with the Channel Islands' Zoological Station will be a department relegated to the conduct of experiments associated with the -in this country-little developed science of economic pisciculture, and in which department it is proposed to award a prominent place to the artificial rearing of lobsters. Experiments made in this direction by the writer some years since at the Manchester Aquarium have decisively shown that the artificial culture of these crustacea on an extended and systematic scale might be developed into a highly important and remunerative industry. In the experiments here referred to it was found that the little lobsters occupied from six to eight weeks in passing through those singular free swimming larval conditions, known respectively as the "Zoea" and "Megalops" stages, antecedent to their assumption of the adult and ambulatory form, and during which short interval they exuviated or cast their shells many times. These initial metamorphoses safely past, their further development to a marketable size, is a comparatively easy task. The scientific culture of the oyster and other edible species will likewise receive attention in association with this undertaking.

The appropriateness of Jersey as a site for this intended Museum of Pisciculture and Zoological Station is at once apparent, the variety and exuberance of the marine fauna of the Channel Islands being such as to assimilate it more closely to that of the Mediterranean than any other one within British waters. The occur. rence on the Channel Islands' coast of the Sea Horse (Hippocampus), Urchin-fish (Diodon), Remora (Echeneis), Electric Ray (Torpedo), and Lancelet (Amphioxus), among the vertebrate group; and of the Hatiotis, Scyllarus, Comatula, Physalia, Velella, Lucernaria, and many others among the invertebrate section, are a few from among many that might be named in demonstration of this fact. The sponge-tribe and the division of the tunicate might be lilsewise specially singled out as attaining upon the shores of these islands a development in both numbers and variety rarely if anywhere else excelled. Unprecedented facilities for the collection of all such marine productions are also afforded by the extraordinary 